\title{
Biopharmaceutical Innovation System in China: System Evolution and Policy Transitions (Pre-1990s-2010s)
}

\author{
Hao Hu${ }^{1}$, Chao-Chen Chung ${ }^{2 *}$
}

\begin{abstract}
Background: This article sets up the initial discussion of the evolution of biopharmaceutical innovation in China through the perspective of sectoral innovation system (SIS).

Methods: Two data sources including archival documentary data and field interviews were used in this study. Archival documentary data was collected from China Food and Drug Administration (CFDA) and Chinese National Knowledge Infrastructure (CNKI). In addition, industrial practitioners and leading researchers in academia were interviewed.

Results: Biopharmaceutical in China was established through international knowledge transfer. The firms played more active role in commercializing biopharmaceutical in China though universities and research institutes were starting to interact with local firms and make contribution to biopharmaceutical industrialization. The transition of the Chinese government's policies continuously shapes the evolution of biopharmaceutical sector. Policies have been dramatic changes before and after 1980s to encourage developing biopharmaceutical as a competitive industry for China.

Conclusion: A SIS for biopharmaceutical has been shaped in China. However, currently biopharmaceutical is still a small sector in China, and for the further growth of the industry more synthetic policies should be implemented. Not only the policy supports towards the research and innovation of biopharmaceuticals in the early stage of development should be attended, but also commercialization of biopharmaceutical products in the later stage of sales.

Keywords: Biopharmaceutical, Sectoral Innovation System (SIS), China, Pharmaceutical Industry, Biotechnology Copyright: @ 2015 by Kerman University of Medical Sciences

Citation: $\mathrm{Hu} \mathrm{H}$, Chung CC. Biopharmaceutical innovation system in China: system evolution and policy transitions (pre-1990s-2010s). Int J Health Policy Manag. 2015;4(12):823-829. doi:10.15171/ijhpm.2015.162
\end{abstract}

\section{Article History:}

Received: 23 April 2015

Accepted: 31 August 2015

ePublished: 3 September 2015

\section{Key Messages}

\section{Implications for policy makers}

- Biopharmaceutical innovation demands the establishment of a sustainable innovation system that needs many efforts across decades.

- Policy focus could emphasize investment in academic research and development to accumulate biopharmaceutical knowledge at the first stage, but also needs to transfer to firm-leading industry-academia cooperation in the following industrialization stage.

\section{Implications for public}

Biopharmaceutical innovation requires long-term investment, which needs the strong support from the public. Considering the significant medical efficacy of biopharmaceutical drugs, public should provide more patience and cognitive support to develop biopharmaceutical in developing countries.

\section{Background}

This article explores the trajectory of biopharmaceutical innovation in China. Biopharmaceutical whose knowledge base is modern biotechnology originally emerged in the United States in the 1970s. Modern biotechnology following the definition of Laage-Hellman et $\mathrm{al}^{1}$ refers to the biotechnology which is developed in the post-genetic engineering era in the 1970s. Besides, in this article we also define traditional biotechnology as the biotechnology developed before the post-genetic engineering era. Indeed the origin of modern biotechnology was the development of recombinant DNA and genetic engineering techniques in the early 1970s in the universities of the United States, such as the University of California, San Francisco, CA, USA. The American pharmaceutical multinational company (MNC), Eli Lilly, as well as the new American biopharmaceutical company, Genentech and the European pharmaceutical MNC, Kabi (Swedish), were the companies which first commercialized the techniques of genetic engineering and applied the techniques for manufacturing pharmaceuticals identified as the biopharmaceutical today. ${ }^{2}$ The innovation system of biopharmaceutical which initially emerged in the United States eventually spilled over to China, the second largest economy all over the world. However, compared with 
the empirical analysis of biopharmaceutical innovation in the United States and Europe which has been well-documented by large quantities of the current literature, ${ }^{3-5}$ the evolution and transition of biopharmaceutical in China only gains limited notice of the existing literature. ${ }^{6}$ Even though the Chinese government has considered biopharmaceutical as one of the strategic industries which would potentially strengthen the leadership of the Chinese economy globally, the transition of government policies and its influence on the evolution of biopharmaceutical innovation system presently remains ambiguous.

This article thus sets up the initial discussion of the evolution of biopharmaceutical innovation system in China through the perspective of sectoral innovation system (SIS). A SIS defines an innovation system by a set of products. The SIS following Malerba ${ }^{7}$ is composed of 3 elements: knowledge and technology, actors and networks, and institutions. In fact, a sector possesses a specific knowledge base and technology, and the actors within the network of the sectoral system are the individuals and organizations, including firms, universities, and research institutes. The actors would adopt the specific knowledge and technology while carry out market and nonmarket interactions for the creation, production and sales of the set of products. The interactions of actors are recognized to be communication, exchange, cooperation, competition and command. Such interactions of actors are indeed shaped by institutions which refer to both the formal (such as laws and regulation) and informal (such as routines and culture) ones. Among the various institutions, government policies are the ones of the most essential institutions in shaping the evolution of the sectoral system. Since biopharmaceuticals are a set of products which are developed upon a particular knowledge and technology and innovated through the interactions of actors within the network, we consider SIS is the most suitable approach towards the analysis of biopharmaceutical innovation.

For the further analysis of the evolution and policy transition of biopharmaceuticals in China, this article is structured as the following. Section Methods presents the methods developed for this study. Section Results describes the results, including ecology and efforts of firms, the exploration of universities and institutes, as well as the design of government policies. Section Discussion discusses the dynamics of sectoral evolution, as well as the policy transition. Finally, section Conclusion concludes the article.

\section{Methods}

Data Collection

We adopt 2 data sources to generate an integrated picture of the evolution of biopharmaceutical innovation in China. The 2 data sources include archival documentary data and field interviews. Each kind of data sources is introduced below. Firstly, archival documentary data were collected from 2 key documentary sources, China Food and Drug Administration (CFDA) and Chinese National Knowledge Infrastructure (CNKI). The former is the most important source of government documents which narrates policies and regulations related to biopharmaceutical in China. The latter is the synthetic collection of databases which include all the academic publications in China. Through CFDA, key government documents of policies and regulations related to biopharmaceutical were extracted. Besides, we used the keyword of 'biopharmaceutical' to search through CNKI and downloaded all the academic publications about biopharmaceutical development. The downloaded publications were checked manually to exclude the publications that were not related to biopharmaceutical in China, such as the review articles about biopharmaceutical development in the United States.

Secondly, field interviews were also conducted. We have interviewed both industrial practitioners and leading researchers in academia. For industrial practitioners, Research and Development (R\&D) and/or marketing managers from 5 Chinese biopharmaceutical companies which have successfully registered and produced the FirstClass New Biopharmaceutical Drugs were interviewed. In sum, 12 industrial practitioners were interviewed. The main interview questions covered company background, knowledge sources of their key biopharmaceutical drugs, internal and external $\mathrm{R} \& \mathrm{D}$ activities, marketing activities, as well as perceived industrial backgrounds and barriers. Every interview was approximately one to one and half an hour in a face-to-face way. Moreover, for leading researchers in academia, 2 Chinese professors majoring in biopharmaceutical research were interviewed to get their ideas about the evolution of biopharmaceutical research in Chinese universities and institutes, the technological cooperation and transfer between academia and industry, government support in biopharmaceutical research and industrialization, and their perceived barriers as well as future strategy for biopharmaceutical development in China.

\section{Data Analysis}

As this research was set to clarify the evolution of Chinese biopharmaceutical innovation system, the 2 data sources collected were jointly analyzed through the perspective of SIS. We especially paid attention to the roles of key actors, firms and universities, and the influence of policies. The data were analyzed through 5 steps. First of all, all the data were categorized into 3 categories: firms, universities and institutes, and policies. Secondly, in each category, the materials and data were ordered in the sequence of years. Thirdly, thematic analysis was carried to identify the main meanings behind the key events. Finally, the findings from each category were analyzed in a crossing way to establish the linkages and dynamics to illustrate the nature of biopharmaceutical innovation system in China.

Results

Efforts of Domestic Firms

The knowledge foundation of biopharmaceuticals was initially developed by China's state-owned enterprises. In 1949, the newly established government of the People's Republic of China built up a comprehensive planned economy system and accelerated efforts to realise selfsufficiency in all products, including pharmaceuticals. Certain state-owned enterprises were thus ordered by the government to produce pharmaceutical products. The majority of these pharmaceuticals were chemical medicines manufactured through chemical engineering. Only a few 
state-owned enterprises were commanded to provide some primary biochemical products, such as insulin extracted from pig pancreases. However, most state-owned enterprises concentrated on the production of chemical medicines and regarded the manufacture of biochemical products as a minor task. ${ }^{8,9}$

It was not until the mid-1980s that the government ordered several state-owned enterprises to develop a number of relatively advanced biochemical products, such as vaccines and blood products. There were rising public concerns about the safety of imported blood products, such as albumin, immunoglobulin and blood coagulation factors. At the same time the demand for vaccines, especially hepatitis B vaccine, was also increasing due to the huge and growing population. Therefore, the government funded seven public research institutes to transfer some traditional biotechnologies such as fermentation methods from the United States for the production of blood products and vaccines. These traditional biotechnologies were then transferred to 30 state-owned enterprises that were involved in manufacture of these products. The state-owned enterprises eventually developed strong capabilities for producing these relatively advanced biochemical products, which they distributed all over the nation. ${ }^{10}$

MNCs only started to sell their biopharmaceuticals in China from the beginning of the 1990s. The MNCs quickly achieved success as dominant players in the Chinese market, particularly the privilege of sales in hospitals, the main marketing channels in China. ${ }^{11,[1]}$ The domestic stateowned pharmaceutical enterprises were thus incentivised to innovate their own biopharmaceuticals. The knowledge base of such biopharmaceuticals was modern biotechnology. Nevertheless, as the domestic state-owned enterprises had not yet accumulated sufficient knowledge of modern biotechnology, it proved very difficult for them to undertake biopharmaceutical production. On the one hand, the stateowned enterprises could not get technology transfers from the MNCs, which were extremely sensitive in protecting their intellectual properties. ${ }^{12}$ On the other hand, these domestic enterprises had limited opportunities to receive practical knowledge of modern biotechnology from the domestic universities or public research institutes, as these learning centres focused mainly on pure academic research. As a result, the state-owned pharmaceutical enterprises had to continuously produce the relatively advanced biochemical products, such as the blood products and vaccines, but were unable to compete with MNCs in the domestic market.

During the early 1990s, the government invested in a small group of new companies that gradually developed their capabilities for innovation in biopharmaceutical products. Kexing Biotech, which was set up in 1989, was the most successful among these new companies. Kexing was the first biopharmaceutical company in China, and it was jointly funded by four public research institutes that collaborated to manufacture and commercialise the result of their cooperative research project, namely 'Recombinant human interferon alb.' In the mid-1990s, Kexing successfully applied genetic engineering for manufacturing this interferon. 'Recombinant human interferon a1b' was thus the first biopharmaceutical product to be developed in China. ${ }^{13,14}$
Only in the middle 1990s did many new biopharmaceutical small and medium-sized enterprises (SMEs) emerged in China. These companies intensified the transfer of modern biotechnological knowledge through 3 routes. First and the most important route, was through Chinese scientists who were trained and worked in the United States and returned to China to set up their new businesses there. ${ }^{15}$ Many of these Chinese scientists had previously conducted specific biopharmaceutical projects, and had innovated particular technologies in the MNCs or at universities in the United States. When these Chinese scientists established their businesses in China, they often received venture capital from the government or state-owned enterprises which had a strong interest in biopharmaceuticals. With such fiscal support, the returned Chinese scientists quickly built up their capabilities to develop biopharmaceuticals. For example, Sunway Biotech was founded in 1995 by a returned Chinese scientist who had helped to develop one of the core genetic technologies of antitumour medicine in the United States. The company received funding from Shanghai Industrial Investment (a state-owned pharmaceutical company) and Shanghai Alliance Investment company (a state-owned venture capital firm). Sunway also obtained substantial $\mathrm{R} \& \mathrm{D}$ funding from the government. With such public financial support, in 2006 the company successfully developed 'recombinant human adenovirus type 5 injection (Oncorine),' which was the world's first oncologic medicine made from viruses. Other companies transferred modern biotechnology through cooperation or acquisition agreements between governments. ${ }^{16}$ For example, Biotech Pharma, which was set up in 2000, received Chinese government support in transferring the biotechnology for producing humanised monoclonal antibodies. The company participated in a project jointly funded by the governments of Cuba and China which resulted in the development of the anti-cancer product 'nimotuzumab injection (taixinsheng).'17 Moreover, some new biopharmaceutical companies benefited from knowledge transfers from domestic universities and research institutes. For instance, Chengdu Huashen Pharma, established in 1996, was licensed by the Fourth Military Medical University and developed its first product, 'iodine tumour necrosis therapy injection (Licartin), which was the world's first biopharmaceutical to target lung cancer with a radioimmunogenic agent. ${ }^{18}$

In most cases, the new pharmaceutical SMEs focused on incremental innovations, with minor improvements to existing biopharmaceuticals. The firms usually did applied research, such as pharmacology tests, animal tests or clinical trials, and they were commonly involved in final marketing activities. These SMEs in fact relied on foreign or domestic academic institutions and MNCs to discover new medicines, and most SMEs were only involved in improving the existing products. Moreover, the SMEs usually delegated individuals or organizational agencies for marketing. Most SMEs were unable to insert into the main marketing channels composed of hospitals, and only a few of these SMEs were able to access to a small part of hospitals for a very short term rather than long term. ${ }^{19}$ With limited innovation and marketing capabilities, these companies were only able to struggle in the domestic market and were incapable to sell their products in foreign countries. Through targeting specific diseases, these 
SMEs tried to avoid competition with each other and aimed to secure niche markets. Indeed, the diseases targeted by these SMEs were usually the ones which were common in China and fully reimbursed by the government. With a cost advantage and incremental development of marketing capabilities in the domestic market, the Chinese biopharmaceutical companies tended to share more and more Chinese market with the MNCs. ${ }^{20,21}$

\section{Exploration of Universities and Institutes}

The main role of universities until the mid-1960s was to deliver education in biology and pharmacy. After the establishment of the People's Republic of China in 1949, only several of the leading universities such as Peking University, Beijing, China and Zhejiang University, Zhejiang, China, founded departments of biology and provided fundamental education to undergraduates. Training in pharmacy was also very limited, and only 11 universities had pharmacy departments. These schools mainly taught chemical pharmaceutical engineering. ${ }^{22}$ The limited efforts in biochemical research were centralised in several public research institutes under the Chinese Academy of Science. The success in creating 'synthetic crystalline bovine insulin' in 1965 was then regarded as the greatest achievement of Chinese science. ${ }^{23}$ However, the Cultural Revolution suspended almost all education and research in universities and public research institutes from 1966 to 1976.

Some universities began to found pharmacy departments near the end of the Cultural Revolution and conducted research into relatively advanced biochemistry. By the 1980s there were 39 universities that provided education in pharmacy. Although chemical engineering was still the main focus of pharmacy education, more and more academics noticed the new developments in biochemistry. ${ }^{22}$ Also, some researchers in the public research institutes of the Chinese Academy of Science began research in biochemistry. Funded by the government, the universities and institutes gained transfers of traditional biotechnology from the United States in areas, such as fermentation methods to help improve the quality of blood products and vaccines. This accumulation of knowledge in the universities and institutes was later transferred to the state-owned enterprises for application in production. Then, inspired by the innovations in biopharmaceuticals from the United States and European countries during the late 1980s, Chinese scientists also began to practise cutting-edge research in biotechnology. In 1987, Chinese scientists discovered 'recombinant human interferon alb, which was the first Chinese biopharmaceutical developed through genetic engineering. This invention was transferred for production to Kexing Biotech in 1989). ${ }^{12}$

Since the mid-1990s, growing numbers of pharmacy departments of universities and public research institutes conducted extensive research in biotechnology and biopharmaceuticals. Numerous departments and programmes for the study of biopharmaceuticals were founded in the pharmacy schools. These departments and programmes acquired huge amounts of $R \& D$ funding from all kinds of government resources, such as the Nature Science Foundation Committee of China, the Ministry of Science and Technology, the Ministry of Health $(\mathrm{MoH})$, and the State
Food and Drug Administration (SFDA). University staffs used such funding to do various research projects, but most of the money was spent on fundamental academic, including embryo, ${ }^{24}$ rather than applied research. The public research institutions were also funded by the government to conduct research in biotechnology. Some institutes were founded specifically to help China catch up with foreign achievements in biotechnology and to develop radical innovations in biopharmaceuticals. In 2005, for example, 8 ministries and departments jointly invested in establishing a new National Institute of Biological Sciences in Beijing, which aimed to achieve the leading academic status in the international arena. ${ }^{25}$

The efforts of universities and research institutes generated great academic achievements after the 2000s. The numbers of published papers and patent applications related to modern biotechnology and biopharmaceuticals tremendously increased. However, knowledge transfer from universities and institutes to industrial firms was limited. Indeed, the universities and research institutes that received significant government funding to conduct pure academic research had limited motivation to cooperate with companies. Furthermore, as the academic assessment and promotion system merely encouraged scholars to achieve academic publications, academics found themselves reluctant to invest their time to industrialise their discoveries. As a result, transfers of technology and spin-off companies were both limited. Most of the growing knowledge in biotechnology was still contained in the universities and research institutes, without being licensed for business applications. ${ }^{25}$

\section{Design of Government Policies}

The Chinese government only noticed the development of biopharmaceuticals in the 1980s. While modern biotechnology was quickly developing in the United States and European countries, China's transformation from a planned to a market economy in 1978 initially involved a policy of encouraging the development of biopharmaceuticals through knowledge transfers from foreign countries. In 1987, the Chinese government introduced its first policy concerning the biopharmaceutical industry, the 'Development Plan for Biological Products Industry.' This 7 -year plan called for investing government funds in public research institutes to develop blood products and vaccines by using traditional biotechnology transferred from the United States. These traditional biotechnologies were then transferred to state-owned enterprises for the production of the biochemical products. Starting in 1989, a policy of 'Firm Finance Control Measures of Biological Products' gave direct tax reductions to firms producing biopharmaceutical products, which helped them improve their financial performance. However, government policy mainly focused on supporting pure academic research. Due to the weak accumulation of biopharmaceutical knowledge and industrial infrastructure, the government did not pay much attention to biopharmaceutical production until the end of the 1990s. ${ }^{26}$ Since 2000, the main purpose of government policy changed. The new goal was for China to catch up to international standards and even become a world leader in biotechnology research. In addition to providing a faster drug registry 
for biopharmaceutical products, ${ }^{26}$ the government's policies promoted both $\mathrm{R} \& \mathrm{D}$ and industrial parks for biopharmaceutical firms. The R\&D funding was directed to companies as well as universities and public research institutes. In 2002, the government founded the Key State Science and Technology Special Project for 'Functional Genomics and Biochips.' This initiative served to fund targeted programmes in universities and public research institutes. ${ }^{27}$

However, the government gradually noticed that merely allocating funding to academic institutions did not speed up industrial development. Therefore, since 2006, the State Development and Reform Commission introduced 'The Pharmaceutical Industry Eleventh Five Development Guidance' to position the biopharmaceutical industry as one of the nation's 6 key industries. This policy involved greater support for companies, universities, and institutes. Moreover, in 2012, the State Council formally identified the biomedical industry as one of the 'strategic emerging industries of China.' This policy shift positioned firms rather than universities as the key leaders in developing biopharmaceuticals in China. ${ }^{27}$ The evolution of policies specific to biopharmaceutical in China is summarized as Table 1 below.

In addition, the government adopted an industrial park policy to develop the biopharmaceutical industry. Indeed, the government hoped to rival the success of industrial parks for biopharmaceuticals in the United States and European countries. Beginning from 1991, China established numerous industrial parks on the national and provincial levels. Then, parks focusing specifically on bio-industries were widely founded since the beginning of 21st century. By 2006 there were more than 400 bio-industrial parks on the national and provincial levels. ${ }^{28}$ According to the Eleventh Five-Year Plan, the National Development and Reform Commission established 22 new national bio-industry bases in 4 batches, which gradually formed as 3 comprehensive regions for the biopharmaceutical industry. These regions included the Yangtze River Delta, Pearl River Delta, and Beijing-TianjinHebei Region. In short, before the 2000s, the main purpose of policy was to transfer traditional biotechnology from overseas, and after 2000s the aim was to catch up and even to lead the world in the development of biotechnology and innovation in biopharmaceutical products. The targets of policy moved from developing theoretical knowledge in academic institutions to enabling practical innovation in companies. ${ }^{29-31}$

\section{Discussion}

Previous research has indicated that pharmaceutical

Table 1. Biopharmaceutical policy evolution in China

\begin{tabular}{|c|c|}
\hline Year & Policy \\
\hline 1987 & 'Development Plan for Biological Products Industry' \\
\hline 1989 & 'Firm Finance Control Measures of Biological Products' \\
\hline 2002 & $\begin{array}{l}\text { Key State Science and Technology Special Project for 'Functional } \\
\text { Genomics and Biochips' }\end{array}$ \\
\hline 2006 & $\begin{array}{l}\text { 'The Pharmaceutical Industry Eleventh Five Development } \\
\text { Guidance' to position the biopharmaceutical industry as one of } \\
\text { the nation's } 6 \text { key industries }\end{array}$ \\
\hline 2012 & $\begin{array}{l}\text { Biomedical industry as one of the 'strategic emerging industries } \\
\text { of China' }\end{array}$ \\
\hline
\end{tabular}

innovation is highly related to the establishment and operation of innovation system. ${ }^{32}$ Especially for emerging pharmaceutical area like biopharmaceutical, its success demands more support from an innovation system. ${ }^{33}$ In fact, biopharmaceutical innovation system in China possessed modern biotechnology as its own knowledge base. The main actors intensively involved in the innovation were firms (especially SMEs), universities and institutes. While these actors carried out market and non-market interactions for the creation, production and sales of biopharmaceutical, the interactions of these actors were extensively shaped by government policies. Following the empirical analysis above, we generates 4 findings that are worth of further discussion. First, biopharmaceutical in China was established through international knowledge transfer. Modern biotechnology such as genetic and monoclonal antibody was only introduced to China in the mid-1990s from overseas, and the introduction of modern biotechnology was through entrepreneurship. The new biopharmaceutical companies which were mainly set up by the Chinese scientists trained in the United States became the main actors to innovate biopharmaceuticals since the mid-1990s. In particular, the establishment of science park in major cities like Shanghai City attracted many returnees who transferred mature biopharmaceutical science and technologies to China. ${ }^{29}$ At the same time, local pharmaceutical firms experimented to get biopharmaceutical technology sources from overseas through diverse forms like patent acquisition or technology cooperation. ${ }^{28}$ With these direct knowledge transfer, China could rapidly catch-up with the frontiers of global biopharmaceutical development, which significantly mitigate its lag behind the global pharmas and established its industrial infrastructure rapidly.

Second, local government and the state-own enterprises which were dominant in manufacturing relatively advanced biochemical products such as blood products and vaccines became the most important investors of these new biopharmaceutical companies. Biopharmaceutical development always faces great financial risks and often requires the support of venture capital. ${ }^{34}$ However, in China the role of venture capital is replaced by local government and pharmaceutical state-own enterprises. Local government seeks to stimulate the foundation of biopharmaceutical industry locally; local pharmaceutical state-own enterprises that are mostly controlled by local governments also want to invest in biopharmaceutical to increase their profitability in the future. While for new biopharmaceutical companies such kind of financial support is less flexible than venture capital, local government and state-own enterprises in fact provided more stable and additional benefits like policy support to the new biopharmaceutical companies.

Third, universities have extensively accumulated knowledge of biopharmaceuticals from the 1980s until the 2010 s. Nevertheless, with the institutions which tended to encourage pure academic research, universities had limited incentives to transfer biotechnologies to the industry. But it is observed that the universities and institutes in China are more and more involved in technology commercialization of biopharmaceuticals. ${ }^{35}$ Through indirect technology consulting and direct technology cooperation, Chinese universities and institutes are accelerating their integration with industry. 
While the direct transfer of innovative biopharmaceuticals is not expected in the short term, the knowledge accumulation in the last three decades is expected to contribute to the industrial development.

Forth, the transition of the Chinese government's policies continuously shapes the evolution of biopharmaceutical sector. In the 1980s, the main focus of national policies was to manufacture primary biochemical products such as blood products and vaccines to supply national demands. Afterwards, the Chinese government began to encourage industrial development of biopharmaceutical products in the 1990s. Entering into the 21st century the government even recognized biopharmaceuticals as the key strategic industry of the nation and the emphasis of policies was to catch-up even to lead the innovation of biopharmaceuticals in the international arena. Besides, the types of policies also change. Before the mid-2000s, the government mainly provided R\&D funding to universities and research institutes. However, after the 2000s the government also considered the importance of the involvement of firms and provided not only R\&D funding, but bio-industrial parks to develop biopharmaceuticals. Indeed the existing literature has noticed the significant role of Chinese government in directing biotechnology R\&D. ${ }^{36}$ The government's policies have transited in an evolutionary way to establish a competitive biopharmaceutical sector. While China has made its first step in promoting biopharmaceutical sector through founding an innovation system, it faces a lot of challenges ahead, particularly compared with the advanced biopharmaceutical economies. ${ }^{20,21}$ Currently biopharmaceutical is still a small sector in China, and for the further growth of the industry more synthetic policies should be implemented. The Chinese biopharmaceutical sector now highly relies on the new domestic enterprises to develop new products, ${ }^{37}$ and the efforts for the commercialization of biopharmaceutical products totally rely on the marketing capabilities of the new SMEs. Nevertheless, these SMEs with relatively limited resources to invest in the sales of biopharmaceuticals are difficult to compete with MNCs even in the domestic market. In practice, the Chinese government extensively supports the research and innovation of biopharmaceuticals in the early stage of development. Yet, while commercialization was totally burdened by domestic SMEs, once the biopharmaceutical SMEs lacks financial resources for further sales in China, they will lack resources for the further innovation of the biopharmaceutical products. The further development of biopharmaceutical products by firms would thus suspended, but presently there is no policy supports towards the successful sales of biopharmaceutical products. Therefore, the future implementation of biopharmaceutical policies must also consider the aspects of sales, including the public purchase of hospitals. In addition, global pharmas are trying to integrate the rising Chinese biopharmaceutical R\&D into their own global R\&D chain and thus compete with domestic SMEs for the resources of early stage results of R\&D. ${ }^{38-40}$ The impact of MNCs on the Chinese biopharmaceutical innovation system needs longitudinal observation.

\section{Conclusion}

In sum, the biopharmaceutical in China was developed through the establishment of an innovation system in an evolutionary way. The dynamics of biopharmaceutical innovation system in China has emerged since the late 1980s and keep evolving up to date. In fact, the original knowledge base of the Chinese biopharmaceutical sector was traditional biotechnology, and modern biotechnology was introduced into the sector only in the late 1980s mainly through a group of Chinese scientists trained in the United States. In practice, the main actors of biopharmaceuticals were initially the state-own enterprises and then a group of new biopharmaceutical SMEs which were set-up in the 2000s and invested by public funds or state-own enterprises. Targeting the specific segment of diseases, these new companies dominated the sales of particular biopharmaceuticals in the domestic market but lacked the capability to compete with their international counterparts in the foreign markets. The Chinese government considered biopharmaceutical as the strategic industry and provided strong guidance to support the development of biopharmaceuticals. It is the dynamics among these components of innovation system that promoted the development of biopharmaceutical in China.

Based on the findings from this study, there are several implications that could be referred. First, international knowledge transfer is necessary to set up the knowledge base and shorten the technological catch-up period of biopharmaceutical. Second, international returnees could play rising roles in realizing biopharmaceutical transfer and innovation rather than formal international agreement. However, cooperation among organizations, particularly, between firms and academia will contribute in a relatively long term. Third, specific policy design for $\mathrm{R} \& \mathrm{D}$ and industrial development are crucial for innovation and commercialization of biopharmaceutical technology.

Ethical Issues

The research is ethically approved by the University of Macau, Taipa, Macau.

Competing interests

Authors declare that they have no competing interests.

Authors' contributions

$\mathrm{HH}$ initiated the topic and the analysis of this article, while CCC helped to formulate the article with theoretical insights.

\section{Authors' affiliations}

${ }^{1}$ Institute of Chinese Medical Sciences, University of Macau, Avenida da Universidade, Taipa, Macau. ${ }^{2}$ Department of Political Science, National ChengKung University, Tainan, Taiwan.

\section{Endnotes}

[1] There is no formal statistical data officially published by the Bureau of Statistics in China. However, according to the survey done by Chinese Pharmaceutical Enterprises Association in 2009, hospitals played the role as the main channels of pharmaceutical sales. MNCs with mature marketing skills towards hospitals had the prior competitive advantage in marketing than the domestic firms. In fact, while the management of the hospitals used to charged higher prices in pharmaceuticals to supplement the deficits of clinical services, the prices of pharmaceuticals in China were usually much higher than costs. The dominance of MNCs was even more obvious since 2000 when the hospitals were commanded by the government to purchase the pharmaceuticals through legal and transparent processes and to reveal the quality of pharmaceuticals. MNCs which were able to produce high quality pharmaceuticals controlled 
$50 \%$ of the pharmaceutical market, and the rest of the $50 \%$ market was shared by large numbers of domestic firms. The main products of MNCs were biopharmaceuticals, while the products of domestic firms were chemical generic medicines. ${ }^{11}$ According to the survey, MNCs were indeed dominant in the sales of biopharmaceuticals.

\section{References}

1. Laage-Hellman J, Rickne A, McKelvey M, eds. The Economic Dynamics of Modern Biotechnology. Cheltenham: Edward Elgar; 2004.

2. McKelvey M. Evolutionary Innovations: The Business of Biotechnology. Oxford: Oxford University Press; 1996.

3. Brink J, McKelvey M, Smith K. Conceptualizing and measuring modern biotechnology. In: Laage-Hellman J, Rickne A, McKelvey $\mathrm{M}$, eds. The Economic Dynamics of Modern Biotechnology. Cheltenham: Edward Elgar; 2004.

4. Kaiser $\mathrm{R}$, Prange $\mathrm{H}$. The reconfiguration of national innovation systems - the example of German biotechnology. Research Policy. 2004;33:395-408. doi:10.1016/j.respol.2003.09.001

5. Senker J. An overview of biotechnology in Europe: firms, demand, government policy and research. In: Laage-Hellman J, Rickne A, McKelvey M, eds. The Economic Dynamics of Modern Biotechnology. Cheltenham: Edward Elgar; 2004.

6. Huang S. How can innovation create the future in a catchingup economy? Focusing on China's pharmaceutical industry. Journal of Knowledge-based Innovation in China. 2012;4:118131. doi:10.1108/17561411211235721

7. Malerba F. Secotral systems of innovation and production. Research Policy. 2002;31:247-264. doi:10.1016/S00487333(01)00139-1

8. Wang YT, Wu WT, Wu WJ. An overview and features of development of Chinese biopharmaceutical enterprises (in Chinese). Pharm Biotechnol. 2010;17:1-14.

9. Liu X, White S. Comparing innovation systems: a framework and application to China's transitional context. Research Policy. 2001;30:1091-1114. doi:10.1016/S0048-7333(00)00132-3

10. DHTI. Annual Report on Bioindustry in China. Beijing: Chemical Industry Press; 2010.

11. Chinese Pharmaceutical Enterprises Association (CPIA). The Report of the Development of Pharmaceutical Industry in China. Beijing: CPIA; 2009.

12. Liu FZ, Li GL. Review and prospect of the Good Manufacture Practice in China (in Chinese). Chinese Pharmaceutical Affairs. 2009;23:286-289.

13. Hu XW, Ma QJ, Zhang SY. Biopharmaceuticals in China (in Chinese). Biotechnol J. 2006;1:1215-1224.

14. Chen Z, Wang H-G, Wen Z-J, Wang Y-H. Life sciences and biotechnology in China. Philosophical Transactions of the Royal Society B. 2007;362:947-957. doi:10.1098/rstb.2007.2025

15. Chen YT, Luo LJ, Zhang YG. Development trajectories in the biotechnology industry: China versus leading countries. China \& World Economy. 2011;19:105-123. doi:10.1111/j.1749124X.2011.01245.x

16. Han P. China's growing biomedical industry. Biologicals 2009;37:169-172. doi:10.1016/j.biologicals.2009.02.010

17. Cai Y. Biotech Pharma: leading firm of antibody producer in the world (in Chinese). China High-Tech Enterprises. 2010;4:62-63.

18. Huashen Pharma: self-innovation for built-to-last (in Chinese). Chinese Journal of Interventional Radiology. 2007;1:92-94.

19. Bao FF. Development of Biopharmaceutical in China: An Analysis Based on Sectoral System of Innovation [master's thesis]. Macau: University of Macau; 2011.

20. Frew SE, Sammut SM, Shore AF, et al. Chinese health biotech and the billion-patient market. Nature Biotechnol. 2008;26:3753. doi:10.1038/nbt0108-37

21. Rezaie R, McGahan AM, Frew SE, Daar AS, Singer PA. Emergence of biopharmaceutical innovators in China, India,
Brazil, and South Africa as global competitors and collaborators Health Res Policy Syst. 2012;10:18-31. doi:10.1186/1478-450510-18

22. $\mathrm{Xu} X Y, Y u$ XM. Reform and prospect of higher education model in China (in Chinese). Chinese University Teaching. 2008;1:2426.

23. Chinese Pharmaceutical Enterprises Association (CPIA). Development Report of Chinese Pharmaceutical Industry (19492009). Beijing: Chemical Industry Press; 2009.

24. Cyranoski D, Reardon S. Chinese scientists genetically modify human embryos. Nature (News). http://www.nature.com/news/ chinese-scientists-genetically-modify-human-embryos-1.17378. Accessed 26 June, 2015. Published 22 April 2015.

25. Zhou Y, Xu GN, Su J, Minshall T. Barriers to entrepreneurial growth: an empirical study on university spin-offs in China. Journal of Science and Technology Policy in China. 2011;2:277294. doi:10.1108/17585521111167289

26. Deng R, Kaitin KI. The regulation and approval of new drugs in China. Drug Inf J. 2004;38:29-39. doi: 10.1177/009286150403800105

27. Wang JH, Chen T-Y, Tsai C-J. In search of an innovative state: the development of the biopharmaceutical industry in Taiwan, South Korea and China. Dev Change. 2012;43:481-503. doi:10.1111/j.1467-7660.2012.01769.x

28. Su Y, Zhang DL, Guan ZH, Liu XB, Ao Y. A brief survey of building biopharmaceutical industrial parks (in Chinese). China Biotechnol. 2011;31:109-112.

29. Zhang F. Building biotech in Shanghai: a perspective of regional innovation system. Eur Plan Stud. 2015;23(10):2062-2078. doi: 10.1080/09654313.2014.1001322

30. Shi $\mathrm{Y}, \mathrm{Hu} \mathrm{H}$, Wang $\mathrm{Y}$. Technology uncertainty and technology sourcing: case study of biopharmaceuticals in China. International Journal of Business Innovation and Research. 2014;8:566-580. doi:10.1504/IJBIR.2014.064614

31. Conglé M. China's regional economic development from a national perspective: the case of the biopharmaceutical industry. In: Leifner I, Wei DY, eds. Innovation and Regional Development in China. Oxon: Routledge; 2014.

32. Malerba F, Orsenigo L. The evolution of the pharmaceutical industry. Business History. 2015;57(5):664-687. doi:10.1080/00 076791.2014.975119

33. Kukk P, Moors EH, Hekkert MP. The complexities in system building strategies-The case of personalized cancer medicines in England. Technol Forecast Soc Change. 2015;98:47-59. doi:10.1016/j.techfore.2015.05.019

34. Chakma J, Sammut SM, Agrawal A. Life sciences venture capital in emerging markets. Nature Biotechnol. 2013;31:195-201. doi:10.1038/nbt.2529

35. Zhang MY, Lu JJ, Wang L, et al. Development of Monoclonal Antibodies in China: overview and Prospects. BioMed Research International. 2015;2015:168935.

36. Zhang F, Cooke P, Wu F. State-sponsored research and development: a case study of China's biotechnology. Reg Stud. 2011;45:575-595. doi:10.1080/00343401003604663

37. Salter B. Biomedical innovation and the geopolitics of patenting: China and the struggle for future territory. East Asian Science Technology and Society. 2011;5:341-357. doi:10.1215/187521601408227

38. Grimes S, Miozzo M. Big Pharma's Internationalization of R\&D to China. Eur Plan Stud. 2015. doi:10.1080/09654313.2015.10 2944

39. Xia C, Gautam A. Biopharma CRO industry in China: landscape and opportunities. Drug Discov Today. 2015;20(7):794-798. doi:10.1016/j.drudis.2015.02.007

40. Shi $Y Z$, Hu H, Wang C. Contract Research Organizations (CROs) in China: integrating Chinese research and development capabilities for global drug innovation. Global Health. 2014;10:16. doi:10.1186/s12992-014-0078-4 